\title{
TECNOLOGIAS DE REDES E PRODUÇÃO COLABORATIVA: O NOVO PARADIGMA DO DESIGN ABERTO
}

Clorisval Pereira Junior

Pontifícia Universidade Católica do Rio de Janeiro (PUC-Rio)

cjnior@gmail.com

Jackeline Lima Farbiarz

Pontifícia Universidade Católica do Rio de Janeiro (PUC-Rio)

jackeline@puc-rio.br

Rejane Spitz

Pontifícia Universidade Católica do Rio de Janeiro (PUC-Rio)

rejane@puc-rio.br

Resumo: Durante o século XX, o campo do design esteve pautado por ideias de racionalidade, padronização e eficiência industrial, associadas ao desenvolvimento de industrias e corporações privadas estimuladas pelo mercado de consumo. À medida em que entram em pauta questões relacionadas a mudanças climáticas, esgotamento de recursos naturais ou crescentes crises sociais, passamos a notar um debate cada vez mais crítico sobre o modelo de desenvolvimento industrial vigente. Com o início do século XXI e a difusão das tecnologias de redes, observamos a emergência de um vigoroso debate sobre a possibilidade de um novo paradigma de produção, mais colaborativo, aberto e socialmente justo. Neste trabalho, vamos apresentar um panorama crítico da produção industrial nas sociedades moderna e pós-moderna, destacando autores do campo do design como Bonsiepe, Frascara, Manzini e Cardoso e autores do campo da filosofia e sociologia, como Lyotard, Lipovetsky e Ricouer. Vamos analisar a emergência da produção colaborativa baseada em redes, comparando o discurso de autores contemporâneos, que defendem o potencial libertário e empoderador das novas tecnologias, como Benkler, Shirky e Tapscott, com o discurso da pedagogia crítica de Freire e Illich. Para concluir vamos analisar algumas características das formas contemporâneas de produção colaborativa, como licenças abertas, bibliotecas compartilhadas, autoria coletiva e obra aberta, à luz de filósofos da linguagem, como Iser, Goulemot, Bakhtin, Eco e Barthes.

Palavras-chave: tecnologias de redes, produção colaborativa, design aberto.

Abstract: During the twentieth century, the field of design was guided by ideas of rationality, standardization and industrial efficiency, associated 
with the development of industries and private corporations stimulated by the consumer market. As issues related to climate change, depletion of natural resources and growing social crisis enter the agenda, we began to notice an increasingly critical debate about the current industrial development model. With the beginning of the XXI century and the spread of network technologies, we observe the emergence of a vigorous debate about the possibility of a new paradigm of production, more collaborative, open and socially fair. In this paper, we present a critical overview of the industrial production in modern and postmodern societies, highlighting authors from the design field such as Bonsiepe, Frascara, Manzini and Cardoso and authors from the field of philosophy and sociology, such as Lyotard, Lipovetsky and Ricoeur. Considering the emergence of a networkbased collaborative production, we will compare the discourse of contemporary authors who defend the libertarian and empowering potential of these network technologies, such as Benkler, Shirky and Tapscott, with the discourse of the critical pedagogy of Freire and Illich. Finally we will discuss some characteristics of these contemporary forms of collaborative production, such as open licenses, shared libraries, collective and open authorship in the light of philosophers such as Iser, Goulemot, Bakhtin, Barthes and Eco.

Keywords: network technologies, collaborative production, open design.

\section{INTRODUÇÃO}

Conforme observado por Cardoso (2012) o sistema industrial que se impôs na Europa e Estados Unidos a partir do século XIX trouxe um aumento na oferta de bens de consumo combinado com uma queda de custos, provocados por mudanças na organização e nas tecnologias de produção, transporte e distribuição. No início do século $\mathrm{XX}$, as primeiras gerações de designers dedicavam-se à tarefa de conformar a estrutura e aparência dos objetos industriais de modo que ficassem mais eficientes e mais atraentes. Com a meta de reconfigurar o mundo, de proporcionar maior conforto e bem estar para todos, por volta da década de 1930 se popularizou o culto da adequação da forma ao seu propósito: a forma segue a função. Esse mote foi o cerne da preocupação dos designers neste cenário da produção industrial.

Segundo Bonsiepe (2011) o discurso projetual predominante até a década de 1950 foi o da produtividade, da racionalização, da padronização. Este modelo projetual serviu para diferenciar o design do campo da arte e da arte aplicada, dando credibilidade à disciplina do design junto às empresas e corporações industriais. Após a Segunda Guerra Mundial, durante a fase de reconstrução, esse discurso se mostrou eficaz para atender às demandas do mercado de bens de consumo por produtos produzidos em série e a preços acessíveis.

À medida em que entram em pauta questões relacionadas ao esgotamento de recursos naturais, degradação ambiental, mudanças climáticas e crises de distribuição de renda, passamos a notar um debate mais crítico sobre o modelo vigente de produção industrial e de desenvolvimento, tanto no setor acadêmico como nos 
setores industrial e governamental. Em contraposição, a partir do início do século XXI, começa surgir um vigoroso debate sobre um novo paradigma de produção, estimulado pela difusão das tecnologias de rede, que seria potencialmente mais colaborativo, aberto e socialmente justo.

Neste trabalho vamos apresentar um panorama crítico da produção industrial nas sociedades moderna e pós-moderna, fazendo um recorte teórico com autores do campo do design, como Bonsiepe, Frascara, Manzini e Cardoso, junto com autores do campo da filosofia e sociologia, como Lyotard, Lipovetsky e Ricouer. Para discutir a emergência da produção colaborativa baseada em redes, vamos comparar o discurso de autores contemporâneos, que defendem o potencial libertário e empoderador das novas tecnologias, como Benkler, Shirky e Tapscott, com o discurso da pedagogia crítica de Freire e Illich. Para concluir vamos analisar algumas características das formas contemporâneas de produção colaborativa, como licenças abertas, bibliotecas compartilhadas, autoria coletiva e obra aberta, à luz de filósofos da linguagem, como Bakhtin, Eco, Barthes e Foucault.

\section{DESENVOLVIMENTO}

\subsection{Críticas à sociedade industrial}

A partir da década de 1960, a responsabilidade social do design passa a ser debatida por diversos autores, acompanhada de uma crítica a um design servil à lógica da produção industrial.

O manifesto First Things First, proclamado pelo designer inglês Ken Garland em dezembro de 1963 durante uma reunião da Society of Industrial Artists e publicado em Londres, em janeiro de 1964, com a assinatura de outros 22 jovens designers gráficos, criticava o desperdício de talento de designers servis ao aparato da publicidade e do mercado de consumo. No manifesto, Garland propõe uma inversão de prioridades. $O$ autor urge para que os talentos e habilidades dos designers sejam usados em propósitos mais nobres, em vez de servirem de instrumento para a venda lucrativa de produtos de consumo, como comida de gato, pastas de dente listradas, loção após barba, dietas para engordar e para emagrecer, cigarros, desodorantes, etc. Garland já apontava uma saturação consumista em nossa sociedade e defendia a necessidade de uma maior consciência social na atuação do designer.

De fato, é notável todo um cenário de crítica à sociedade de consumo que se observa a partir da década de 1960.

Debord publicou a primeira edição de "A Sociedade do Espetáculo" em 1967. Sua obra serviu de pedra de ignição para os levantes de maio de 68 em Paris. 0 autor criticou a ilusão de consumo construída pela sociedade industrial onde a vida se esvai na fumaça da representação. Debord observou que a sociedade industrial construiu uma realidade irreal, uma fabricação de alienação, destinada à manutenção do ciclo do consumo, onde o ter é mais importante que o ser (Debord \& Vague, 2012). Na sociedade do espetáculo, a relação social passou a ser mediada pelas imagens e pelas representações. A vida passou a se dar no campo da ilusão fazendo sentido a partir do consumo das representações. Para Debord, quanto mais contemplamos o espetáculo, quanto mais aceitamos reconhecer-nos nas imagens dominantes, menos compreendemos nossa própria existência, nossos próprios desejos. 
Na abertura de seu livro "Design para um mundo real", Papanek (1977) alerta que o designer pode ser um profissional perigoso, que pode causar danos à sociedade. Para o autor apenas uma profissão poderia ser mais insincera que o design: a publicidade, quando se dedica a convencer as pessoas a comprar coisas que não necessitam, com dinheiro que não possuem, para impressionar pessoas a quem não Ihes importam. Papanek clamou contra o mundo industrial da ilusão, da representação irreal. O mundo real não é o mundo dos cenários idílicos, perfeitos, das campanhas publicitárias. O mundo real não é um modelo criado para representar um padrão de consumo a ser atingido. Como observado por Cardoso (2012), no mundo real encontramos a fome, a pobreza, a discriminação racial, a guerra, a corrida armamentista, a crise ambiental. Papanek chamou o designer para atuar nesse cenário real onde o design pode servir como um instrumento de transformação social em vez de ser usado como uma ferramenta cosmética de venda.

A partir dos anos 1970, diferentes autores trataram da função social do design e da atuação do designer como um agente de transformação social. Gert Selle (1973) se apoiou na Teoria Crítica da Escola de Frankfurt, para discutir uma ação afirmativa para o Design, envolvendo ideologia e utopia. Tomás Maldonado (1972) observou a degradação ambiental causada pela sociedade industrial de consumo e tratou da esperança projetual, da necessidade do designer agir com autonomia e consciência social. Bonsiepe (1978, 1986 e 2006), desde a década de 70, tem observado os problemas da dependência tecnológica e industrial dos países em desenvolvimento frente aos países desenvolvidos e tem discutido a relação entre design e democracia no sentido de se buscar uma autonomia no projeto de design. Frascara (2000) destacou a importância da aproximação do campo do design com o campo das ciências sociais no desenvolvimento de projetos mais orientados a benefícios sociais que a interesses comerciais. Manzini (2008) tem discutido a importância da sustentabilidade no desenvolvimento de projetos de design e vem apontando o potencial da inovação social, de novas organizações sociais baseadas em redes de colaboração, como um caminho para a mudança do paradigma vigente da produção industrial.

Essa crítica no campo do design, pode ser discutida de forma mais ampla com base em autores do campo da filosofia e da sociologia que debatem as sociedades moderna e pós-moderna. Lipovetsky (2004) caracteriza a transição da modernidade para a pós-modernidade como um novo arranjo do regime do tempo social, onde se observa tanto a passagem do capitalismo de produção para uma economia de consumo e de comunicação de massa, como a substituição de uma sociedadedisciplinar por uma sociedade-moda completamente reestruturada pelas técnicas do efêmero, da renovação e da sedução permanentes. Nessa sociedade do efêmero, deseja-se cada vez menos a repetição dos modelos do passado, e busca-se cada vez mais a novidade como regra e como organização do presente.

Para Lipovetsky (2004), no cenário da pós-modernidade o Estado recua, a religião e a família se privatizam, a sociedade de mercado se impõe. Surge o culto à concorrência econômica, à ambição técnica, aos direitos do individuo. Esta nova modernidade desregulamentada e globalizada apoia-se essencialmente em três axiomas constitutivos: o mercado, a eficiência técnica, o individuo.

Segundo Lyotard (1979) o cenário da pós-modernidade caracterizaria o fim das grandes narrativas ou meta-narrativas, esquemas totalitários de conhecimento, em favor de uma pluralidade de narrativas produzidas no cenário da tecnologia e da 
comunicação de massa. Nesse cenário, nossa sociedade se torna cada vez mais fragmentada, mais dependente da produção simbólica. Ricoeur (2012) observa que na transição para uma sociedade mais individualista ocorre uma ampliação progressiva das relações interpessoais diretas para as relações simbólicas. Nas relações sociais diretas as mediações simbólicas são fracamente tematizadas uma vez que compartilhamos experiências mútuas. Na passagem para a contemporaneidade anônima, aumenta-se a necessidade de mediações simbólicas e os papéis sociais passam a ser tipificados, como os Tipos-Ideias de Max Weber. A contemporaneidade perde o caráter do compartilhar de experiências e a imaginação passa a suprir o papel do engajamento mutuo. A ilusão do espetáculo de Debord assume o papel da realidade.

Para Klein (2002), essa mediação simbólica, essa ilusão do espetáculo, foi assumida pelas marcas corporativas. As grandes corporações transnacionais dominaram o espaço de significação social. Nossa personalidade, nossa interação social se dá a partir das marcas que consumimos. O tênis que você calça, o computador que você usa, a bebida que mata sua sede, a música que você ouve são símbolos construídos para alimentar a cadeia de consumo e produção industrial. Essa construção simbólica se torna ainda mais eficiente com o auxílio da comunicação de massa. Klein critica o cenário vigente de patrocínio corporativo agressivo e de privatização do espaço público e da vida cultural. Mas ao mesmo tempo observa o surgimento de uma nova mentalidade anticorporativa, de um movimento de troca de experiências libertadoras baseado na nova rede informacional global.

\subsection{Tecnologias de redes e a produção colaborativa}

A transformação do modo de produção da sociedade industrial para a sociedade informacional, baseada nas tecnologias de informação e comunicação interconectadas, trouxe novos cenários de inovação tecnológica e inovação social abrindo novas oportunidades para a atuação do Design.

Castells (2004) observou a sociedade informacional como uma forma específica de organização social onde a geração, o processamento e a transmissão da informação e do conhecimento se convertem em fontes de produtividade e de poder. A autor examinou como os processos de globalização gerados pelo modelo econômico desenvolvimentista, apoiados pela tecnologia, podem se desenvolver com caráter elitista e marginalizar os grupos sociais excluídos das redes de informação.

De fato, as economias informacionais industriais podem gerar informação, conhecimento e produção cultural de forma hierarquizada e institucionalizada. Em cenários de concentração de poder, a manipulação de símbolos é destinada à uniformização cultural e geração de uma massa de consumidores passivos. Grandes corporações fazem o seu branding de forma global cruzando culturas e muitas vezes extinguindo redes de produção local. Grandes corporações de mídia dominam a comunicação global e local impondo valores culturais e repertórios de massa que sufocam diversidades culturais.

No entanto, como observado por Benkler (2006), a queda do custo da tecnologia e a disseminação global de tecnologias de interconexão em rede trouxeram novas oportunidades para produzir e trocar informação, conhecimento e produção cultural. Benkler, assim como Tapscott (2011) e Shirky (2008), observam o surgimento de uma nova economia, uma economia colaborativa e interconectada. 
Esta nova economia seria caracterizada por um modo de produção descentralizado, não-hieraquizado, não proprietário, não mercantilizado e não institucionalizado.

Benkler (2006) e Tapscott (2011) observam que as novas tecnologias de colaboração online trazem cenários de produção social são caracterizados por:

- Propriedade intelectual aberta, recursos compartilhados e acessíveis a todos. (Novas formas de licenciamento de conteúdo, WikiCommons, Creative Commons, softwares de código aberto, bibliotecas e bases de dados abertas, etc.)

- Alcance global, capacidade de formação de coletivos e comunidades sem restrição geográfica.

- Produção por pares, colaborativa, sem hierarquia autoritária. (Redes P2P, redes sociais e comunidades online).

Este cenário criou um campo de disputa pela ecologia informacional onde arranjos coletivos não hierarquizados passam a competir com instituições corporativas centralizadoras de poder. O compartilhamento de MP3 em redes P2P balançou a indústria das gravadoras musicais. O Linux, um sistema operacional gratuito, colaborativo e de código aberto balançou gigantes como a Microsoft e a IBM. O Skype balançou as grandes companhias de Telecomunicação. A Wikipédia balançou grandes editoras como Encarta e Grollier. Redes de crowdfunding estão transformando os modelos de negócio empresariais.

Benkler (2006) apontou o surgimento das redes informacionais interconectadas como uma oportunidade para criarmos e ocuparmos o ambiente informacional como indivíduos autônomos, cidadãos, participantes em prol do grupo.

Illich (1971) e Freire (1968) no final da década de 60, início da década de 70 já chamavam a atenção para os aspectos alienantes da institucionalização e hierarquização social. Illich, muito antes da Internet, preconizou o surgimento das sociedades conviviais, onde a educação e a construção da autonomia se daria a partir de teias de aprendizagem basedas em:

- Amplo acesso aos objetos de conhecimento (conteúdo não proprietário, de acesso livre).

- Redes de intercâmbio de habilidades não autoritárias (convívio de aprendizagem em vez de aprendizagem por autoridade professoral)

- Redes de colaboração entre pares.

Mesmo sem ter em mãos as tecnologias de rede atuais, as proposições radicais de Illich e Freire deram origem a diversos experimentos sociais, que preconizaram práticas colaborativas muito em voga nos dias de hoje.

\subsection{Design aberto}

Contrariamente ao paradigma da sociedade industrial que usa o modelo de patentes e de propriedade intelectual com uma visão de vantagem competitiva, nas redes informacionais colaborativas a vantagem se dá em compartilhar recursos e 
conhecimento. A potência de criação se amplia a partir do momento que temos acesso aos recursos e ao conhecimento produzido por toda a comunidade.

Peer-to-Peer (P2P): Conforme observado por Benkler (2006), desde 2002 houve uma corrida para desenvolver o maior supercomputador em capacidade de processamento. A primazia que era dos Estados Unidos foi superada pelo Japão que desenvolveu o NEC Earth Simulator. Logo foi recuperada pelos Estados Unidos com o IBM Gene Blue, com capacidade de processamento em mais de 30 Teraflops. No entanto, essa corrida desconsiderou que, ao mesmo tempo, o projeto Seti@Home usou a capacidade ociosa de processamento de milhares computadores caseiros em todo o mundo, conectados via Internet, gerando uma rede colaborativa que atingiu mais de 80 Teraflops de capacidade de processamento, batendo de longe o IBM Gene Blue. Ou seja, computadores caseiros ociosos e conectados em rede formaram o maior supercomputador global, a um custo infinitamente inferior aos altos investimentos corporativos da NEC e IBM.

Do-It-Yourself (DIY): As redes informacionais oferecem diferentes cenários e oportunidades para compartilhar recursos e conhecimento. O professor e inventor indiano Arvind Gupta criou o projeto Toys from Trash (Gupta, 2013), que mantem uma biblioteca com milhares de objetos de aprendizagem em forma de brinquedos que reproduzem experimentos científicos. Gupta utilizou um site com instruções completas e vídeos caseiros em um canal do Youtube para dar acesso global a milhões de pessoas interessadas em aprender a montar seus próprios experimentos científicos usando materiais tão simples como lixo reciclado.

Crowdsourcing: Outro aspecto interessante no cenário da produção social em redes é o aspecto colaborativo do trabalho sem uma estrutura hierárquica de poder. Conforme observado por Shirky (2008). A principal razão do sucesso do projeto da Wikipédia está na motivação em colaborar com o projeto. Todos podem participar. Qualquer um pode sugerir um tópico para a comunidade. Toda contribuição é incremental, adiciona conhecimento ao todo. Em uma empresa tradicional, criar um produto como a Wikipédia teria um custo bem mais alto devido ao ônus do gerenciamento de pessoas e tarefas com papéis hierárquicos em uma estrutura de autoridade.

Licenças Abertas: Diferentemente dos modelos de propriedade intelectual privada, novos modelos de licenciamento no mundo digital estão permitindo um acesso mais livre e aberto ao conhecimento. No campo da produção de software, é notável a cena de produção do software livre, com ênfase na licença GNU/GPL, e das licenças Creative Commons no campo dos conteúdos digitais (Lessig, 2004).

Obra aberta: Os cenários das redes informacionais implicam em uma forma de trabalho mais aberta, onde a própria natureza da obra construída coletivamente é em si mais aberta. Eco (2013) introduziu o conceito de obra aberta considerando a intenção do autor em permitir uma maior entropia na intepretação do leitor, um maior número de interpretações possíveis. Neste sentido, discutiu a estrutura da obra considerando uma ausência de fechamentos, que obriga o leitor a novas inferências e 
novas construções de significados. Bakhtin (2006) apontou o processo de comunicação dialógico como uma interação a partir da produção de enunciados, onde cada enunciado é um elo da cadeia dos atos de fala. Toda inscrição na obra prolonga aquelas que a precederam, trava uma polêmica com elas. Iser (1999) abordou a abertura na obra literária como potência. Os espaços abertos ou indeterminados deixados pelo autor seriam campos de produção para o leitor, espaços para criação de novos significados e interpretações.

Bibliotecas Compartilhadas: Mais do que a obra em si, no campo da produção social em redes colaborativas é também importante a compreensão do que Goulemot (2001) trata como fora-do-texto. Goulemot observou que toda obra literária traz na sua produção de sentidos os aspectos exteriores ao texto propriamente dito, que são a história, a fisiologia e a biblioteca: a história trata do contexto cultural no qual estamos inseridos; a fisiologia estaria relacionada às condições físicas de interação com a obra; e a biblioteca da conexão com as outras histórias vividas.

Autoria Coletiva: Também é interessante notar como as relações entre autor e leitor também ficam ainda mais difusas nas redes de colaboração. Barthes (2004) já falava que para que aconteça o nascimento do leitor, é preciso que ocorra a morte do autor. Ao autor caberia escrever a obra lançando mão do dicionário, do tecido de signos, compartilhado com a sua cultura. Para Foucault (1969), a autoria é uma atribuição, uma designação de função de autor para organizar a existência, circulação e funcionamento dos discursos em uma determinada cultura.

Partindo do referencial teórico de Eco (2013), Goulemot (2001), Iser (1999), Bakhtin (2006) e Barthes (2004), onde a produção de linguagem, do ato de escrita e de leitura, considera o espaços não-ditos, indeterminados e abertos da obra, bem como da importância do contexto cultural da cadeia de produção, podemos observar como ocorrem determinados cenários de produção social nas redes colaborativas. Um caso exemplar se dá no contexto das ações de game modding.

No contexto dos games, um MOD é uma modificação da obra original. MODs podem ser desenvolvidos tanto pelos criadores originais da obra como por qualquer leitor/usuário. Um MOD é um código adicional que pode ser adicionado à obra original modificando a estrutura da mesma, seja inserindo novos personagens, novos ambientes, novos contextos. Em games como o Minecraft, Batttlefield, World of Warcraft, Grand Theft Auto, é comum a formação de comunidades de desenvolvedores de MODs. Os autores originais permitem e as vezes apoiam esse desenvolvimento. Essa extensão da obra cria um maior envolvimento entre leitor e autor. Mais que isso cria uma comunidade que gira em torno da produção e ressignificação da obra. Esse fora-do-texto, como indicado por Goulemot, envolve a participação em fóruns de desenvolvedores na Internet, canais no Youtube e em redes sociais onde usuários recriam e contam suas histórias pessoais. Surge todo um aparato transmidiático vinculado não apenas à obra mas também à construção de bibliotecas compartilhadas e à formação de uma história cultural.

As novas formas de autoria, coautoria, modificação, remixagem das obras na sociedade digital, demandam novos paradigmas de trabalho e novas discussões sobre 
propriedade intelectual e produção colaborativa com maior participação da sociedade civil.

\section{CONCLUSÃO}

A partir da discussão apresentada, podemos observar que os manifestos e críticas contra a os excessos da industrialização e contra o estímulo ao consumo, partilhado por diversos teóricos críticos da sociedade moderna e da globalização, produziram um campo de interesse de um design voltado para o bem comum da sociedade.

Os novos paradigmas de produção em rede representam uma oportunidade para o campo de design, para atuação em projetos de produtos e serviços destinados à coletividade. Nestes contextos de redes colaborativas, mais do que trabalhar com a especialidade de conformar produtos para o mercado de consumo, observamos novas possibilidades para o campo do design em projetos mais colaborativos e abertos destinados mais ao desenvolvimento social que ao desenvolvimento industrial. São oportunidades de projetos desenvolvidos em comunidades de produção aberta, em contextos não privatizados e não hierarquizados, com capacidade de ação menos dependente do espetáculo da sociedade industrial.

Com base nos pressupostos discutidos, entendemos que capacidade do designer de se adaptar a esse novo modo de produção, mais aberto e colaborativo, dependerá da sua capacidade de desenvolver novas habilidades e competências, bem como de atuar como um agente de transformação social, exercendo tanto o seu caráter técnico como o ideológico.

Novas abordagens metodológicas, como o Human Centered Design Kit (2015) desenvolvido pela IDEO em colaboração com organizações não governamentais, apontam para novas estratégias de projeto focadas em pesquisa e prototipação colaborativas. Autores como Brown (2009) e Cross (2011), destacam a importância do design thinking em processos de inovação social. Neste sentido, é fundamental o debate sobre abordagens de Design Participativo e Co-Design (Ehn, 2008; Sanders \& Stappers, 2008).

À medida em que o Design se abre para o coletivo, o designer passa a atuar não mais para um público alvo, mas em colaboração com o público, em conjunto com atores empoderados e autônomos. Neste cenário, podemos vislumbrar a potência do Design como um agente de transformação social.

\section{REFERÊNCIAS}

BAKHTIN, Michail. Marxismo e filosofia da linguagem. São Paulo: Hucitec Editora. 2006

BARTHES, Roland. O Rumor da Língua. São Paulo: Martins Fontes. 2004

BENKLER, Yochai. The Wealth of Networks: How Social Production Transform

Markets and Freedom. Yale University Press. 2006

BONSIEPE, Gui. Design and Democracy. In: Design Issues, Volume 22, Number 2 Spring 2006

BONSIEPE, Gui. A tecnologia da tecnologia. São Paulo: Edgard Blücher. 1983 
BONSIEPE, Gui. Diseño industrial: tecnologia y dependência. México: Edicol. 1978. BROWN, Tim. Change by design: How design thinking transforms organizations and inspire innovation. Harper Collins. 2009

CARDOSO, Rafael. Design para um mundo complexo. São Paulo: Cosac Naif. 2012

CASTELLS, Manuel. The Network Society: A Cross-Cultural Perspective. Cheltenham: Edward Elgar. 2004

CROSS, Nigel. Design Thinking: Understanding How Designers Think and Work. Berg Publishers. 2011

DEBORD, Guy; VAGUE, Tom. Society of the Spectacle. Bread and Circuses, Kindle Edition. 2012

ECO, Umberto. Obra Aberta. 9. ed. São Paulo: Perspectiva. 2013.

EHN, P. Participation in Design Things. In: Participatory Design Conference, 08, 2008, Bloomington, Indiana. Proceedings. Bloomington, ACM Press, p. 92-101. 2008

FOUCAULT, Michel. $\mathbf{O}$ que é um autor? Bulletin de la Societé Française de Philosophic, 630 ano, no 3, julho-setembro de 1969

FRASCARA, Jorge. Diseño Gráfico para la Gente: Comunicaciones de masa y cambio social. Buenos Aires: Ediciones Infinito. 2000

FREIRE, Paulo. Pedagogia do oprimido. 1968

GOULEMOT, Jean Marie. Da leitura como produção de sentidos. In: CHARTIER, Roger.

Práticas de leitura. 2. ed. São Paulo: Estação Liberdade, 2001.

GUPTA, Arvind. Books and Toys Gallery. Disponível em:

http://www.arvindguptatoys.com. Acessado em Julho, 2013.

IDEO. The Field Guide to Human-Centered Design. IDEO.org. 2015. Disponível em: http://www.designkit.org/resources/1. Acessado em Junho, 2016.

ILLICH, Ivan. Deschooling Society. Harper \& Row. 1971

ISER, Wolfgang. O ato da leitura. Vol. 2. Editora 34. 1999

KLEIN, Naomi. Sem logo: a tirania das marcas em um planeta vendido. Rio de Janeiro: Record. 2002

LESSIG, Lawrence. Free Culture: How Big Media Uses Technology and Law to Lock Down Culture and Control Creativity. New York: Penguin Press. 2004

LIPOVETSKY, Gilles. Os tempos hipermodernos. São Paulo: Barcarolla, 2004.

LYOTARD, Jean-François. La condition postmoderne: rapport sur le savoir. Les Éditions de Minuit. 1979

MALDONADO, Tomás. Design, Nature, and Revolution: Toward a Critical Ecology. Harper \& Row. 1972

MANZINI, Ezio. Design para sustentabilidade e inovação social: comunidades criativas, organizações colaborativas e novas redes projetuais. Rio de Janeiro, EPapers. 2008 
PAPANEK, Victor. Disenãr para el Mundo Real. Madrid, H. Blume Ediciones. 1977 RICOEUR, Paul. Tempo e Narrativa. Vol.3. O Tempo Narrado. São Paulo: Martins Fontes. 2012

SELLE, Gert. Ideología y utopia del diseño. Barcelona, Editorial Gustavo Gili, 1973. SHIRKY, Clay. Here Comes Everybody: The Power of Organizing Without Organizations. Penguin Press, Kindle Edition. 2008

SANDERS, Elisabeth B.; STAPPERS, Pieter J. Co-creation and the new landscapes of design. IN: CoDesign. Vol. 4, Iss. 1, 2008

TAPSCOTT, Don e WILLIAMS, Anthony D. Wikinomics: How Mass Collaboration Changes Everything. Atlantic Books, Kindle Edition. 2011 